\title{
The Absorption of Nitrate and Phosphate from Urban Sewage by Blue-Green Algae (Spirolina Platensis) (An Alternative Medium) as Application for Removing the Pollution
}

\author{
${ }^{* 1,2}$ LAVAJOO, F; ${ }^{1}$ THAHERIZADE, M; ${ }^{1}$ DEHGHANI, M
}

\author{
${ }^{I}$ Department of marine biology, Faculty of Sciences, University of Hormozgan, P.O.Box 3995, Bandar abbas, Iran. \\ ${ }^{2}$ Young Researcher and Elite Clube, Islamic Azad University, Bandar abbas Branch, Iran. P.O.Bbox: 79159-1311(Corresponding \\ Number:+989378096174)
}

\begin{abstract}
The applications of blue green algae for the treatment of urban and industrial sewage have received more attention during the recent years because they have the capacity to use nitrogenous compounds, ammonia and phosphates. In this study aimed to evaluate the ability of Spirolina platensis for absorption of nitrate and phosphate from urban sewage. The experiment was conducted in 6 treatments as a growth medium. To test these predictions, we conducted a 15 days in indoor place under similar laboratory conditions at temperature $\left(30^{\circ \mathrm{C}} \pm\right.$ $\left.2^{\mathrm{oC}}\right)$, Light $(2500 \pm 500)$ Lux, $\mathrm{pH}$ between 8.0 and 11 and with constant aeration. Regarding the culture media, a higher algal density was observed in the cultivation developed at treatment 5 $\left(824 \pm 10^{2}\right.$ cell. $\left.\mathrm{mL}^{-1}\right)$. In our results showed higher efficiencies of phosphorus removal by $S$. platensis as compare to nitrate removal thus, $S$. platensis would be effective for nitrate removal only at relatively low concentrations and phosphorus removal at high concentrations. Chlorophyll-a, content in treatment 3 was higher than other treatments. Kruscal-Wallis test showed a significant difference in treatments at the level of $\mathrm{P}<0.05$. Thus, we recommend here that Spirolina platensis to be better candidate for absorption phosphate more than nitrate and it could be used for the removal or biotransformation urban sewage.

(c) JASEM
\end{abstract}

http://dx.doi.org/10.4314/jasem/v19i3.15

KEY WORDS: Blue-Green Algae, Spirolina, Nitrate, Phosphate, Sewage, Pollution

\section{INTRODUCTION:}

Nowadays pollution of water by nutrients, heavy metals, organic and inorganic pollutants is a major problems concern of the society (Abdel-Raouf et al., 2012). The industrial and big cities generating a wastewater that it's impact on health of people and environment (Shastri and Raval, 2012) and must be treated before being entered into sea or fresh water(Ruiz-Martinez et al., 2012). The use of microalgae to remove additional dissolve nutrients is a valuable effective way for waste water treatment (Velichkova et al., 2014). As essential algae bioremediation properties is that they used for a broad range of purposes such as: depletion of chemical and biochemical oxygen demand (COD, BOD), depletion of Coliform bacteria, depletion of $\mathrm{N}$ and/or $\mathrm{P}$, and also for the depletion of heavy metals (Hasan et al., 2014). In the past it's usual to use microalgae for example Chlorella, Chlamydomonas, Spirulina, Scendesmus, Nostoc and Oscillatoria for wastewater treatment (Sharma and Khan, 2013).For the growth of microalgae need three primary nutrients: carbon, nitrogen, and phosphorus. The growth conditions of microalgae are depend on several factors, such as light intensity, photoperiod, temperature, $\mathrm{CO} 2$ flow rate, nutrient composition, etc( Becker EWB and Borowitzka, 1988). The nitrogen and phosphorus of agricultural industrial and urban waste discharged are main cause of eutrophication (karthikeyan et al., 2010). Rapid industrialization in Iran has resulted increase urban waste which is traditionally discharged in to open area or nearby river or sea, causing a number of environmental problems (e.g. plant life, animal life, drinkable water, agricultures and human). In the present study Spirolina platensis was selected as a model species of marine blue green algae to investigate the biotransformation of urban waste and whether they can be used as a valuable index depletion effects on nitrogen and phosphorus.

\section{MATERIALS AND METHODS:}

Test Species: In this study the microalgae culture of marine blue green algae (Spirolina platensis) was obtained from the Phytoplankton Culture Laboratory, of institution Persian Gulf and Omani Sea of Hormozgan in Iran. The urban sewage was collected from discharged refinery site of Bandar abbas.

Experimental Design: In the laboratory, the samples of sewage were filtered through a $25 \mathrm{~mm}, 3 \mu \mathrm{m}$ glass microfiber filters $(\mathrm{GF} / \mathrm{C})$ mounted on a Millipore filtration unit and sterilized by autoclaving at $121^{\circ} \mathrm{C}$ for 15 minutes. The culture growth medium prepared with three replicates for conducting the experiments and the duration was 15 days under similar 
laboratory conditions at temperature $\left(30^{\mathrm{oC}} \pm 2^{\mathrm{oC}}\right)$, Light $(2500 \pm 500)$ Lux, pH between 8.0 and 11 , that adjusted by electronic $\mathrm{pH}$ meter (ELICO, Model LI 120) and with constant aeration. Treatments were: 1) Spirolina was cultivated in $\mathrm{f} / 2$ Medium based on (Guillard, 1975). 2) Spirolina was cultivated in $80 \%$ of filtered seawater and $20 \%$ urban waste. 3) Spirolina was cultivated in $60 \%$ of filtered seawater and $40 \%$ urban waste. 4) Spirolina was cultivated in $40 \%$ of filtered seawater and $60 \%$ urban waste. 5) Spirolina was cultivated in $20 \%$ of filtered seawater and $80 \%$ urban waste. 6) Spirolina was cultivated in $100 \%$ urban waste.

Cell density and Growth Rate: The cell growth was monitored by measuring cell numbers by manual counting under the binocular light microscope. Growth rates were calculated as $\mu$. day ${ }^{-1}$ according to the following formula $\mu=\left(\mathrm{N} 1 / \mathrm{N}_{0}\right) / \mathrm{t}$; Where, N0 and $\mathrm{N} 1$ represent cell density at the start and the end of the growth period, and $\mathrm{t}$ are the time between measurements (in days).

Physicochemical and statistical analysis: Water quality analysis of ammonia and phosphorus (orthophosphate) determination were based on Phenate Method and Vanadomolybdo phosphoric Acid Method adapted from the Standard Method for the Examination of Water and Wastewater (APHA, 2005). Sampled water was clarified from the MA and EM biomass by centrifugation at $5000 \mathrm{rpm}, 15 \mathrm{~min}$ to obtain clear supernatant which was subjected immediately to water quality analysis for the determination of ammonia and phosphorus. Nitrate and chlorophyll-a, were also measured by spectrophotometer UV/visible (Varian-carry 100) according to Manual of Oceanographic Observations and Pollutant Analysis Methods procedures (Marine environment assessment marine meteorology, 1999). For statistical purposes, by using Shapiro-Wilk test, it was shown that comparison between different treatments does not follow the normal distribution; therefore, one-way ANOVA Kruscal-Wallis test was used to compare the means treatments. The results were analyzed statistically by using Spss 17 software and graphical analyses were performed using Microsoft Office Excel.

\section{RESULTS AND DISCUSION}

In the experiment, highest cellular densities (cell. $\mathrm{mL}^{-}$ ${ }^{1}$ ) for Spirolina platensis in different days and different dilutions of the urban sewage were observed on the seventh day at treatment $5\left(824 \pm 10^{2}\right.$ cell. $\left.\mathrm{mL}^{-1}\right)$ (Fig.1). The statistical analysis $(\mathrm{p}<0.05)$ of the cell density in different days showed significant differences between tested treatments. The results impact of different treatment and different days on growth rates of Spirolina platensis showed a reciprocal influence $(\mathrm{R}=0.73)$. In this study the highest biomass (Chlorophyll-a) registered for Spirolina .SP was in treatment $3(0.21 \pm 0.07)$. The nitrate concentration (Mean \pm SD) in different dilutions of the urban effluent was highest is treatment $3(0.27 \pm 0.21)$ and for phosphate was highest in treatment5 (18.15 \pm 4.26). For concentration of nitrate in different treatment Spirolina platensis significant differences were not observed $(\mathrm{p}<0.05)$ but phosphate showed a significant differences $(p<0.05)$ (Fig.4, 5). Kruscal-Wallis test showed a significant difference in treatments at the level of $\mathrm{P}<0.05$ (Table 1). The result indicates that no one of treatments have not constant additional growth thus at initial, the growth rate increase then in delay phase it decrease. The growth rate $S$. platensis in treatment 6 was highest in day 11 that it related to its high nutrients. On the other hand, the cell concentration continued to increase until the eleventh day of cultivation and after that decreased (Table 2). From the results it is concluded that the best conditions for growth Spirolina is in $80 \%$ urban waste because it reach the maximum cell concentration at seventh day (Table 2). In addition, comparatively the growth rate in treatment 1 (without urban sewage) was high in day11 which denoted that the organic matter produced of algal cell death after day10 through its impact on Spirolina growth rate. The relationship between different treatment and different time's analysis with two ways- ANOVA showed a positive correlation, $\mathrm{R}$ Squared $=0 \quad 0.822$ (Adjusted R Squared $=0.725$ ) at the level of $\mathrm{P}<0.05$, it indicated that they positive relationship have a positive impact on Spirolina platensis growth. Interesting things about this specious Spirolina platensis was after exponential phase, the growth rate tends to stabilize or low, when compared to prior phases. Lourenço in 2006 explained that the duration of this phase depends on the availability of necessary nutrients. Karthikeyan in 2010 suggested that the higher values of ammonia, nitrite, nitrate and the growth of $C$. simplex was slightly enhanced with lower concentration and inhibited at higher concentrations of the effluent. These results indicated that the physiological activity of $S$. platensis was not reduced by high nitrate concentrations. According to Coelh (2013) the nitrate (NO3) is the most stable form of nitrogen present in seawater and absorbed by the algal. After exponential phase, the growth rate tends to stabilize and is always decreased, when compared to initial phases, thus the duration of this phase depends on the availability of essential nutrients. The chlorophyll-a, content generally increased with the incising nitrate concentrations and in treatment 3 was higher than other treatments. This suggested at low $\mathrm{N}$ concentrations, chlorophyll formation was limited by $\mathrm{N}$ supply while excessive $\mathrm{N}$ did not access. Nitrogen was one of the main limiting nutrients to growth phytoplankton in all nutrient limitation experiments (Livingston et al., 2002). 
Prased (1982) and Geddes (1984) suggested that $\mathrm{P}$ and $\mathrm{N}$ to be two key factors of eutrophication. So, it is necessary additional treatment being explored to decrease eutrophication of water environment (Sawayama et al., 2000). In our results showed higher efficiencies of phosphorus removal by $S$. platensis as compare to nitrate removal thus not only optimum laboratory condition affected on Spirolina but also nutrients are important for that growth. Nitrate removal yield is depend on nitrate level in the medium, i.e. the lower the nitrate concentration, the higher the removal. Thus $S$. platensis would be effective for nitrate removal only at relatively low concentrations and phosphorus removal at high concentrations. Results of Costa et al in 2004 on urban secondary sewage demonstrated that this media to be satisfactory for growth Tetraselmis chuii (Prasinophyceae) and Dunaliella viridis thus it could be used by semi intensive aquaculture systems. Tam and Wong, 1996 suggested that chlorella vulgaris removed significantly more $\mathrm{NH} 3$ of sewage. The phycoremediation was very efficient, cost effective and eco-friendly indicating that microalgae has vital role in the removal of different pollutants from wastewater. The pollutants removal efficiency of Oscillotaria was higher as compare to Nostoc which

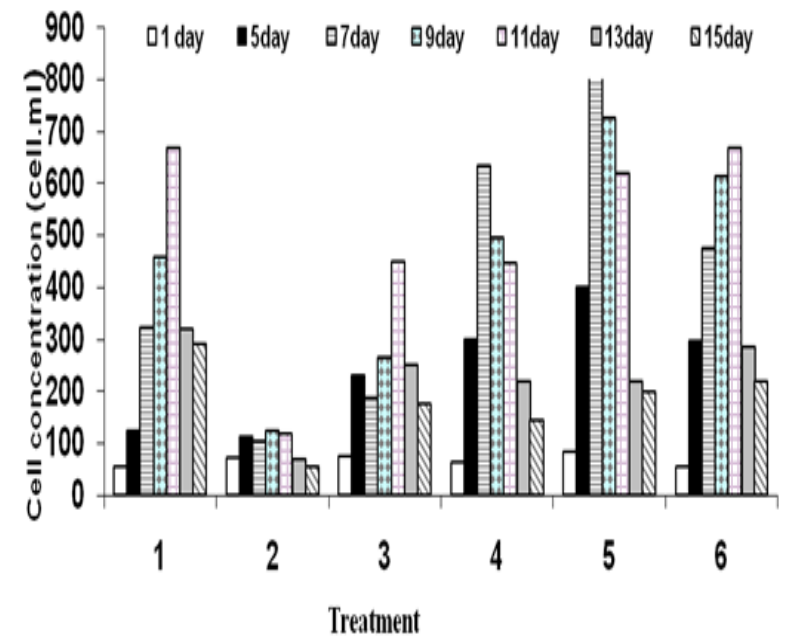

Fig.1: The Cell concentration (Mean $\pm \mathrm{SD}$ ) of Spirolina platensis with different dilutions of the urban effluent in different days. can be recommended for phycoremediation purpose. The used of numerous laboratory and pilot studies of this process and properties of microalgae to removal algae for depletion or removal nutrients such as nitrate and phosphate was studied about more than 50 years ago by Oswald and Gotaas (1957), as this essential properties is that cultured algae in sewage nutrient (Zhu et al., 2008). Prased (1982) and Geddes (1984) suggested that $\mathrm{P}$ and $\mathrm{N}$ to be two key factors of eutrophication. So, it is necessary additional treatment being explored to decrease eutrophication of water environment (Sawayama et al., 2000). Initial density is one of biotic factors significantly influencing algal growth thus higher algal density increased the growth and the higher nutrient depletion efficiency (Lau et al., 1995). Coelh et al in 2013 presented growth of the microalgae Tetraselmis tetrathele decreased more rapidly in the culture medium Guillard f/2 comparison to Conway medium that is related to its the lower nitrate availability. In our study we recommend here that Spirolina platensis to be better candidate for absorption of phosphate more than nitrate and it could be used for the removal or biotransformation urban sewage.

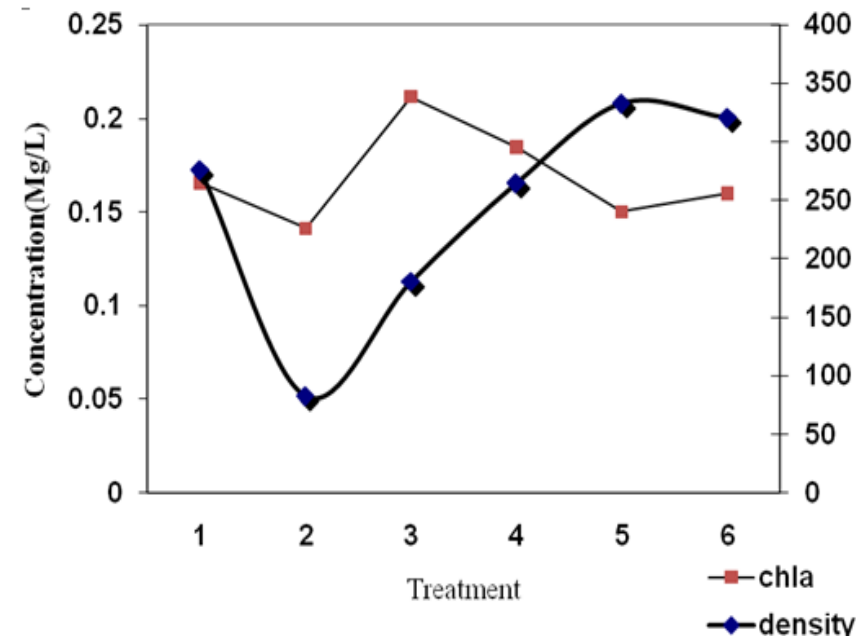

Fig. 2. The relationship between chlorophyll$\mathrm{a}$ and density $\left(\mathrm{Mg} . \mathrm{L}^{-1}\right)$.

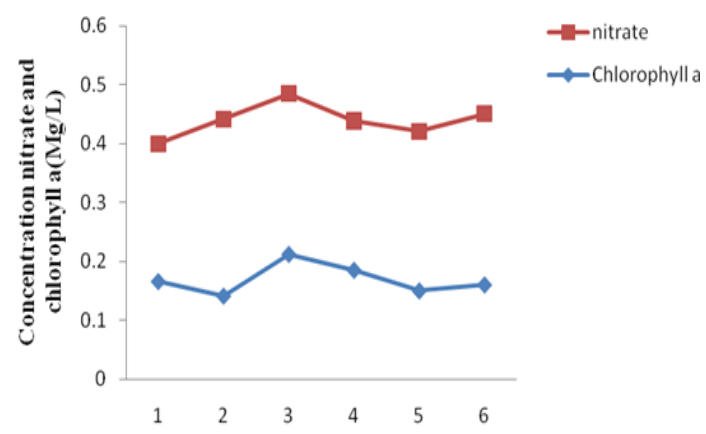

Fig.3: The comparison between chlorophyll- $a$ and nitrate Concentration $\left(\mathrm{Mg} . \mathrm{L}^{-1}\right)$ of Spirolina platensis at 6treatments $\quad{ }^{7} \cdot{ }^{1,2^{*}}, M$ in day 15.

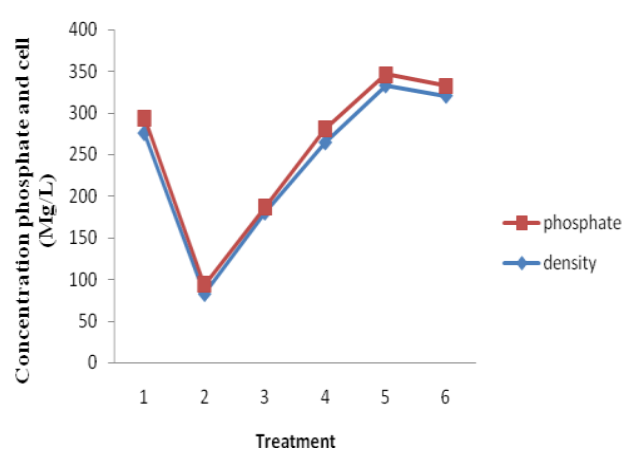

Fig.4: The relationship between chlorophyll $a$ and phosphate concentration $\left(\mathrm{Mg}\right.$. $\left.\mathrm{L}^{-1}\right)$ of Spirolina plantensis at 6treatments of the urban sewage in day 15. 
Table 1: Kruscal-Wallis test amongst all of treatments at the level of $\mathrm{P}<0.05$.

\begin{tabular}{lllllll}
\hline & Treatment & Treatment & Treatment & Treatment & Treatment & Treatment \\
Test & $1 \& 2$ & $1 \& 3$ & $1 \& 4$ & $2 \& 3$ & $2 \& 4$ & $3 \& 4$ \\
Chi-Square & 2.33 & 5.69 & 4.13 & 1.33 & 1.69 & 0.09 \\
df & 1 & 2 & 3 & 1 & 2 & 1 \\
Asymp. Sig. & 0.12 & 0.05 & 0.25 & 0.13 & 0.030 & 0.03 \\
\hline
\end{tabular}

Table 2: Cell concentration (cells. $\mathrm{L}^{-1} \times 10^{2}$ ) at different treatments between days 1 -15

\begin{tabular}{|c|c|c|c|c|c|c|c|c|}
\hline Days & & $1-3$ & $3-5$ & $5-7$ & $7-9$ & $9-11$ & 11-13 & 13-15 \\
\hline \multirow{6}{*}{ 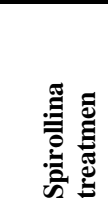 } & 1 & $56 \times 10^{2}$ & $123 \times 10^{2}$ & $334 \times 10^{2}$ & $461 \times 10^{2}$ & $670 \times 10^{2}$ & $319 \times 10^{2}$ & $292 \times 10^{2}$ \\
\hline & 2 & $72 \times 10^{2}$ & $112 \times 10^{2}$ & $105 \times 10^{2}$ & $127 \times 10^{2}$ & $119 \times 10^{2}$ & $70 \times 10^{2}$ & $57 \times 10^{2}$ \\
\hline & 3 & $75 \times 10^{2}$ & $230 \times 10^{2}$ & $188 \times 10^{2}$ & $268 \times 10^{2}$ & $450 \times 10^{2}$ & $250 \times 10^{2}$ & $179 \times 10^{2}$ \\
\hline & 4 & $64 \times 10^{2}$ & $300 \times 10^{2}$ & $634 \times 10^{2}$ & $496 \times 10^{2}$ & $488 \times 10^{2}$ & $219 \times 10^{2}$ & $147 \times 10^{2}$ \\
\hline & 5 & $85 \times 10^{2}$ & $400 \times 10^{2}$ & $824 \times 10^{2}$ & $727 \times 10^{2}$ & $622 \times 10^{2}$ & $220 \times 10^{2}$ & $202 \times 10^{2}$ \\
\hline & 6 & $56 \times 10^{2}$ & $296 \times 10^{2}$ & $477 \times 10^{2}$ & $615 \times 10^{2}$ & $671 \times 10^{2}$ & $286 \times 10^{2}$ & $221 \times 10^{2}$ \\
\hline
\end{tabular}

\section{REFERENCES:}

Abdel-Raouf, N; Al-Homaidan, AA; Ibraheem, IBM (2012). Microalgae and wastewater treatment. Saudi Journal of Biological Sciences 19: 257-275

APHA, AWWA, WEF(2005). Standard Methods for the Examination of Water and Wastewater. American Public Health Association Publication, Washington, 21th edition.

Azarpira, H; Behdarvand, P; Dhumal, K; Pondhe, G (2014). Comparative studies on phycoremediation of sewage water by using blue green algae. International Journal of Biosciences 4: 58-64

Becker EWB, MA; Borowitzka, LJ (1988). Micro-algae for human and animal consumption, in Micro-algal biotechnology. Cambridge University press: Cambridge: $222-256$

Coelho, A A d C; Barros, M UG; Bezerra, JHC; Silva, JWAd; Moreira, RL; Farias, WLR(2013). Acta Scientiarum Biological Sciences 35(2):163-168

Guillard, RRL (1975). Culture of phytoplankton for feeding marine invertebrates. In: Smith, W L; Chanley, M H (Eds.), Culture of Marine Invertebrate Animals. Plenum Press New York 29-60

Geddes, MC (1984). Limnology of lake Alexandrina River, Muarry, South Australia and the effect of nutrients and light on the phytoplankton. Aust J Mar Fresh Water Res 35 (4): 399-416

Hasan, R; Zhang, B; Wang,L; Shahbazi, A (2014). Bioremediation of Swine Wastewater and biofuel potential by using Chlorella vulgaris, Chlamydomonas reinhardtii, and Chlamydomonas debaryana. Journal of Petroleum \& Environmental Biotechnology 5(175):3348.4168

Karthikeyan, p; Jayasudha, s; Sampathkumar, p; Manimaran, k; Santhoshkumar, c; Ashokkumar, s; Ashokprabu, v(2010). Effect of Industrial Effluent on the Growth of Marine =Diatom, Chaetoceros simplex (Ostenfeld, 1901). J Appl Sci Environ Manage 14 (4): $35-37$

Lau, PS;Tam, NFY; Wong, YS(1995). Effect of algal density on nutrient removal from primary settled wastewater. Environmental Pollution 89: 59-66

Livingston, R; Akshithala, J; Prasad, K; Xufeng, N; McGlynn,SE (2002). Effects of ammonia in pulp mill effluents on estuarine phytoplankton assemblages: field descriptive and experimental results. Aquatic Botany 74: 343-367

Oswald, WJ; Gotaas, HB(1957). Photosynthesis in sewage treatment. Trans Am Soc Civil Eng 122: 73-105

Ruiz-Martinez A, Martin-Garcia N, Romero I, Seco A, Ferrer J. 2012. Microalgae cultivation in wastewater: Nutrient removal from anaerobic membrane bioreactor effluent. Bioresource Technology 126: 247-253

Sawayama, S; Hanada, S; Kamagata, Y(2000). Isolation and characterization of phototrophic bacteria growing in lighted up flow anaerobic sludge blanket reactor. J Biosci Bioeng 89 (4): 396-399

Sharma, GK; Khan, SA (2013). Bioremediation of sewage wastewater using selective algae for manure production. International Journal of Environmental Engineering and Management 4: 573-580

Tam, NFY; Wong, YSb(1996). Effect of ammonia concentrations on growth of chlorella vulgaris and nitrogen removal from media. Bioresource Technology 57 (1996): 45-50

Velichkova, K; Sirakov, I; Stoyanova, S (2014). Biomass production and wastewater treatment from aquaculture with Chlorella vulgaris under different carbon sources. Scientific Bulletin 18:83-88

Zhu, G; Peng, Y; Li, B; Guo, J; Yang, Q; Wang, S( 2008). Biological removal of nitrogen from wastewater. Rev Environ Contam Toxicol 192: 159-195 